\title{
Research on Application of Full Attribute 3D Design Model in Engineering
}

\author{
Xinqian $\mathrm{Xu}^{1}$, Rui $\mathrm{Xia}^{2}$, Lai $\mathrm{Xu}^{3}$, Xiwen $\mathrm{Hu}^{4, *}$ \\ 1,2,3 State Grid Jiangsu Electric Power Co., Ltd., Jiangsu Province, Nanjing, 211102 \\ ${ }^{4}$ Jiangsu Electric Power Design Institute Co., Ltd., Jiangsu Province, Nanjing, 211102
}

\begin{abstract}
In order to take full advantages of the integration of 3D technology graphics and data, this paper proposes the concept of a full-attribute 3D model that satisfies the full-process data application of substation engineering construction. All stages of engineering construction extract the required data from the fullattribute 3D model for calculation, Analysis, statistics, management and other functions, to achieve all-round coverage of three-dimensional data information from design to construction and construction management, laying the foundation for data circulation and management of the entire life cycle of substation projects. A method of applying a full-attribute three- dimensional model for construction, operation and maintenance management is proposed, which lays a foundation for the realization of refined, digital and intelligent project management.
\end{abstract}

\section{Introduction}

With the increasing difficulty of power grid construction and construction management requirements, it is urgent to adopt more advanced technologies to solve many problems involved in substation engineering design, construction, construction management, and operation \& maintenance, such as insufficient design refinement and construction, The schedule is out of line with the actual situation, etc., to improve the level of substation engineering design, construction management, and operation and maintenance. With the development of computer graphics and software and hardware, all walks of life in our country have begun to apply 3D technology extensively and deeply. The application of the whole process of substation construction based on 3D technology is not only the trend of power system development, but also the inevitable progress of the times [1-2].

\section{Current Status of Research on Application of $3 \mathrm{~d}$ Technology in Substation Engineering}

\subsection{Research status abroad}

When 3D technology first appeared in the 1980s, international engineering companies optimized the design process mainly according to the requirements of enterprise informatization and the changes brought about by $3 \mathrm{D}$ technology [3].
With the development and application of 3D technology, well-known foreign engineering companies have gradually begun to consider the process management of the entire life cycle of the factory. This "engineering life cycle" concept emphasizes a complete engineering project, which should include design, construction commissioning, operation and decommissioning. This kind of integrated research on the whole life of the project is the main working idea of the large-scale foreign engineering company to carry out $3 \mathrm{D}$ technology research [4].

\subsection{Research state in China}

When the 3D technology just appeared in the 1980s, the domestic electric power design institutes had already begun to study the CALMA 3D system on the APOLLO workstation, but the design work still relied on traditional design methods and the application of 3D technology was not mature enough. With the rapid development of computer technology and network technology, threedimensional technology in domestic electric power design institutes is moving from a partial feasibility exploration to a mature application stage [5-6].

The application and development of 3D technology in domestic substation engineering is divided into three stages: the first stage of the 3D technology mainly uses the basic graphics platform for 3D modeling, focusing on the realization of $3 \mathrm{D}$ visual display effects; the second stage is through the introduction of domestic and foreign advanced 3D software Platform, and carry out secondary development and customization to meet the application needs of domestic projects[7-8]; the third stage is the advanced application of $3 \mathrm{D}$ technology, from the

Corresponding author: huxiwen@jspdi.com.cn 
perspective of project life cycle data management and application, 3D technology is realized Management application in all stages of design, construction, supervision, operation and maintenance. At present, domestic research is mainly concentrated in the second stage, and the research content of the third stage is rarely involved.

\section{Full-Attribute 3d Model Research}

Three-dimensional technology is the basis for realizing a new generation of digital, virtual, and intelligent information platforms, and realizes the unification of graphics and engineering data. Compared with twodimensional, three- dimensional technology is characterized by two aspects: space and data. Using spatial characteristics, 3D technology can realize complex underground pipeline layout, cable optimization layout, collision inspection, construction simulation, visual display, etc. Utilizing the characteristics of data, different attributes can be assigned to different objects to realize main wiring design, electrical calculation, engineering quantity statistics, material reporting, construction progress management, operation and maintenance management, etc.

For 3D technology, 3D model is the core content and the carrier of 3D data. Therefore, the management and application of 3D data information in the whole life cycle of a project should focus on the information requirements of 3D models. From the perspective of the whole life cycle of the project, research the needs of 3D data information in various stages of design, construction, supervision, supervision, operation and maintenance, and carry the information with $3 \mathrm{D}$ models to realize the complete $3 \mathrm{D}$ data information from design to construction and construction management. Position coverage, laying the foundation for project life cycle management. This model that can reflect the data requirements of each stage of project construction is called the "full attribute" model.

\subsection{Full-attribute 3D model modeling principles}

Combined with the application requirements of the threedimensional model data for the whole life cycle of substation engineering construction, the full-attribute three-dimensional model modeling should conform to the following basic principles:

1)Normative. Meet the relevant design specifications, the owner's relevant regulations on three-dimensional modeling, material procurement, and digital handover.

2)Standardization. Three-dimensional modeling should fully inherit and adapt to the infrastructure standardization results of the owner company.

3)Demand. Three-dimensional modeling should meet the application requirements of three- dimensional model data in all units, majors and various stages.

4)Balance. Three-dimensional modeling includes general drawings, primary and secondary electrical, civil engineering, plumbing and other majors, covering various content such as equipment, facilities, and components, and runs through the entire life cycle of engineering design, construction, operation and maintenance, etc. stage. The wider and deeper the modeling range and depth, the more refined the design, but at the same time the lower the design efficiency. Therefore, it is necessary to find a balance between fine design and improving design efficiency.

5)Incremental. Three-dimensional modeling should be refined and expanded as the project implementation phase deepens, and its degree of refinement and attribute amount should show a gradual increase trend.

\subsection{Data requirements for 3D models in the design phase}

The data requirements for the $3 \mathrm{D}$ model in the design stage are mainly reflected in the following aspects:

1) Extract the main technical parameters in the model to form the technical parameter content in the main wiring diagram.

2) Extract relevant technical parameters in the model and complete relevant electrical calculations.

3) Extract relevant statistical parameters in the model, complete statistical work such as material inventory and engineering quantities.

4) Extract the material parameters in the model to assist in the completion of material reporting.

Based on the above content, the 3D model at the design stage should contain the following attributes: (Take a 500kV 750MVA transformer as an example).

\subsection{Data requirements for 3D models during construction}

Construction management is mainly divided into schedule management, quality management and cost management.

\subsubsection{Project schedule management data requirements}

Using three-dimensional model data for project schedule management, that is, its core elements, project duration, project deliverables, completed projects, resource consumption, etc., are transformed into data information that can be used for calculation and statistics, and the construction progress is simulated and the construction is formed Schedule Gantt chart. At the same time, combined with real-time construction information input, and planned construction progress in the form of data, charts and other forms of visual and dynamic comparative analysis, guide construction plan management, and finally achieve dynamic and precise control and intelligent management of project progress, reducing construction delays Risk, improve construction efficiency.

Based on the above content, the three- dimensional model that meets the needs of schedule management should contain the following attributes in table 2.

Construction management can extract the detailed schedule attributes of specific equipment or buildings for refined management, and can also extract the planned attribute values of a certain area (such as $500 \mathrm{kV}$ power 
distribution device area, road area, etc.) or an entire

building to perform milestones node plan control.

Table 1. 500kV 750MVA transformer three- dimensional model attribute parameter table based on design requirement

\begin{tabular}{|c|c|c|c|}
\hline Property Characteristics & \multicolumn{2}{|l|}{ Property Name } & Property Content \\
\hline & \multicolumn{2}{|l|}{ Voltage Level } & $500 \mathrm{kV}$ \\
\hline & \multicolumn{2}{|l|}{ Equipment Name } & Transformer \\
\hline & \multicolumn{2}{|l|}{ Statistical Unit } & \\
\hline & \multicolumn{2}{|c|}{ General Equipment Number } & $5 \mathrm{~T} 2 \mathrm{~B}-750$ \\
\hline & \multicolumn{2}{|l|}{ Equipment Type } & $\begin{array}{l}\text { three-phase, auto-coupling, three- } \\
\text { winding }\end{array}$ \\
\hline & \multicolumn{2}{|c|}{ Rated Frequency } & 50 \\
\hline & \multicolumn{2}{|c|}{ Rated Capacity(high/medium/low) } & $750 / 750 / 250$ \\
\hline & \multicolumn{2}{|c|}{ Rated voltage (high/medium/low) } & $525 / 230 / 36$ \\
\hline & \multicolumn{2}{|c|}{ Voltage regulation method } & without excitation \\
\hline & \multicolumn{2}{|c|}{ Pressure regulating position } & Medium voltage side line end \\
\hline & \multicolumn{2}{|c|}{ Pressure regulation range } & $\pm 2 \times 2.5$ \\
\hline \multirow[t]{9}{*}{ Basic Attribute Field } & \multirow{3}{*}{$\begin{array}{l}\text { Short-circuit } \\
\text { impedance }\end{array}$} & $\begin{array}{lll}\text { (reserved) } & \text { small reactance } \\
\text { grounding } & & \end{array}$ & 14 \\
\hline & & $\begin{array}{l}\text { High-low short circuit } \\
\text { impedance }\end{array}$ & 47 \\
\hline & & $\begin{array}{l}\text { Medium-low short circuit } \\
\text { impedance }\end{array}$ & 30 \\
\hline & \multicolumn{2}{|l|}{ Cooling method } & OFAF or ODAF \\
\hline & \multicolumn{2}{|l|}{ Phase number } & Three phase \\
\hline & \multicolumn{2}{|l|}{ Connection group label } & YNa0d11 \\
\hline & $\begin{array}{l}\text { Bushing type current } \\
\text { transformer (neutral } \\
\text { point side) }\end{array}$ & Number of windings & 4 \\
\hline & & Accuracy level & TPY/TPY/5P20/0.5 \\
\hline & & Current ratio & $2500 / 1$ \\
\hline
\end{tabular}

Table 2. Three-dimensional model attribute table to meet schedule management requirements (take equipment installation as an example

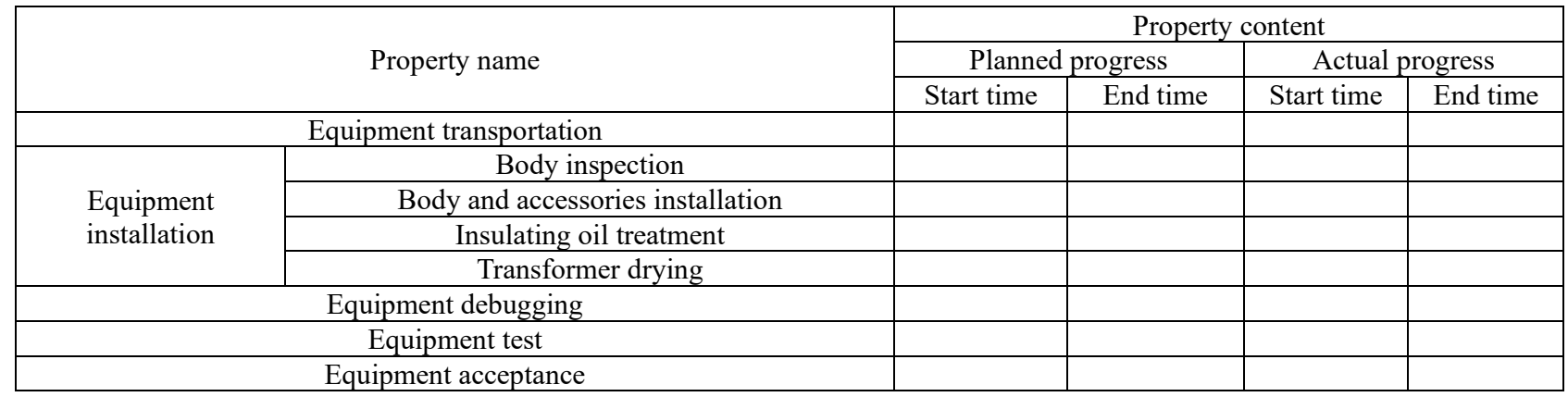

*Note: The actual progress will be tracked and filled in by the person in charge of the specific equipment during the construction period.

\subsubsection{Engineering quality management data requirements}

The core elements of project quality management are standard process management, common quality fault prevention, construction risk early warning, etc. The implementation of standard process and common quality fault prevention and control is compared and analyzed with pictures and three-dimensional models, and the construction sites of the third level and above risk Carry out digital signage to realize risk warning, and use threedimensional models to visualize construction plans for important risk points. Finally realize the visual quality control of project construction.

Based on the above content, a 3D model that meets engineering quality requirements should contain the following attributes.

Combining with the time attribute in progress control, an important risk point can be warned and avoided in advance. 
Table 3. Three-dimensional model attribute table to meet quality management requirements

\begin{tabular}{|c|c|c|c|}
\hline Property characteristics & \multicolumn{2}{|c|}{ Property name } & Property content \\
\hline \multirow{9}{*}{ Quality Management Field } & Standard Process & Number & $\begin{array}{l}\text { Fill in the Standard Process } \\
\text { Number }\end{array}$ \\
\hline & \multicolumn{2}{|c|}{ Construction key points } & $\begin{array}{l}\text { Fill in the standard process } \\
\text { construction key points }\end{array}$ \\
\hline & \multicolumn{2}{|c|}{ Legend } & Give a typical legend \\
\hline & \multicolumn{2}{|c|}{ Actual construction effect } & $\begin{array}{l}\text { Give a picture of actual } \\
\text { construction effect }\end{array}$ \\
\hline & \multicolumn{2}{|c|}{ Common quality disease prevention measures } & $\begin{array}{l}\text { Fill in the quality prevention } \\
\text { measures }\end{array}$ \\
\hline & \multirow{4}{*}{ Risk warning } & Risk level & Fill in the risk level \\
\hline & & Preventive measures & $\begin{array}{l}\text { Fill in specific preventive } \\
\text { measures }\end{array}$ \\
\hline & & Simulation video & $\begin{array}{l}\text { The risk simulation video is given } \\
\text { in the form of a link }\end{array}$ \\
\hline & & Study records & $\begin{array}{l}\text { Important risk points need to link } \\
\text { to upload study records }\end{array}$ \\
\hline
\end{tabular}

\subsubsection{Project cost management data requirements}

Using the key cost information in the three- dimensional model to generate construction drawing budget; integrate the general cost requirements into the project cost management module, compare the results of construction drawing budget in real time, and show the unreasonable project cost items in the form of charts or data to realize the cost Control and control the total cost of the project within a reasonable range.

The following takes the main equipment in the installation project as an example. According to

the engineering quantity calculation rules of the "Electric Power Construction Project Budget Quota", the attribute data that needs to be extracted for the installation project is shown in the following table 4.

As can be seen from the above table, the main technical parameters in section 2.2 have basically met the needs of technical and economic budget statistics, and only the equipment code and equipment weight need to be increased.

\subsection{Data requirements for 3D models during operation and maintenance}

The operation and maintenance stage focuses on the realtime operating status and monitoring data of the substation. The data comes from online monitoring equipment, cameras, etc. The information extracted is the data measured by the equipment itself rather than the additional data in the 3D model, so there is no need to Additional data attributes are added to the model to meet the needs of the operation and maintenance phase. For specific applications in the operation and maintenance phase, see Chapter 5.

\subsection{Full-attribute 3D model that meets the data requirements of the entire process of engineering construction}

Based on the research results in chapters 2.2-2.4, it is a full-attribute three-dimensional model that meets the data requirements of the entire process of construction. Relevant information can be extracted from the model for construction management needs at all stages of construction.

\section{Research on theapplication of 3D technology in engineeringconstruction}

The application of 3D technology in the construction phase, that is, adding information dimensions such as attributes, time, technical parameters, and management requirements to the digital model to form a complete multi- dimensional construction model, and perform fullscale, omni-directional, and complete processes on the computer in advance The three- dimensional digital construction simulation, combined with the rehearsal effect, adjusts and optimizes the construction plan and resource allocation, making equipment and material management, labor allocation, construction machinery management and other tasks more reasonable, effective and economical.

Table 4. The installation project needs to extract the $3 \mathrm{D}$ model attribute data table 


\begin{tabular}{|c|c|c|c|c|c|c|}
\hline Equipment name & Quantity & Name & Specification & Model & Voltage class (kV) & Capacity (kVA or Ah) \\
\hline Transformer & $\sqrt{ }$ & $\sqrt{ }$ & $\sqrt{ }$ & $\sqrt{ }$ & $\sqrt{ }$ & $\sqrt{ }$ \\
\hline $\begin{array}{l}\text { SF6 circuit breaker } \\
\text { installation }\end{array}$ & $\sqrt{ }$ & $\sqrt{ }$ & $\sqrt{ }$ & $\sqrt{ }$ & $\sqrt{ }$ & \\
\hline $\begin{array}{l}\text { Installation of SF6 fully } \\
\text { enclosed } \\
\text { electrical appliances (GIS) }\end{array}$ & $\sqrt{ }$ & $\sqrt{ }$ & $\sqrt{ }$ & $\sqrt{ }$ & $\sqrt{ }$ & \\
\hline HGIS and COMPASS & $\sqrt{ }$ & $\sqrt{ }$ & $\sqrt{ }$ & $\sqrt{ }$ & $\sqrt{ }$ & \\
\hline $\begin{array}{l}\text { Indoor isolation switch } \\
\text { installation }\end{array}$ & $\sqrt{ }$ & $\sqrt{ }$ & $\sqrt{ }$ & $\sqrt{ }$ & $\sqrt{ }$ & \\
\hline $\begin{array}{l}\text { Outdoor double-post } \\
\text { isolating switch installation }\end{array}$ & $\sqrt{ }$ & $\sqrt{ }$ & $\sqrt{ }$ & $\sqrt{ }$ & $\sqrt{ }$ & \\
\hline $\begin{array}{l}\text { Outdoor three-post } \\
\text { isolating switch installation }\end{array}$ & $\sqrt{ }$ & $\sqrt{ }$ & $\sqrt{ }$ & $\sqrt{ }$ & $\sqrt{ }$ & \\
\hline $\begin{array}{l}\text { Outdoor single-post (GW6) } \\
\text { isolation switch installation }\end{array}$ & $\sqrt{ }$ & $\sqrt{ }$ & $\sqrt{ }$ & $\sqrt{ }$ & $\sqrt{ }$ & \\
\hline $\begin{array}{l}\text { Open type combined } \\
\text { electrical installation }\end{array}$ & $\sqrt{ }$ & $\sqrt{ }$ & $\sqrt{ }$ & $\sqrt{ }$ & $\sqrt{ }$ & \\
\hline $\begin{array}{l}\text { Single-phase grounding } \\
\text { switch installation }\end{array}$ & $\sqrt{ }$ & $\sqrt{ }$ & $\sqrt{ }$ & $\sqrt{ }$ & $\sqrt{ }$ & \\
\hline $\begin{array}{ll}\text { Voltage } & \text { transformer } \\
\text { installation } & \end{array}$ & $\sqrt{ }$ & $\sqrt{ }$ & $\sqrt{ }$ & $\sqrt{ }$ & $\sqrt{ }$ & \\
\hline $\begin{array}{l}\text { Indoor current transformer } \\
\text { installation }\end{array}$ & $\sqrt{ }$ & $\sqrt{ }$ & $\sqrt{ }$ & $\sqrt{ }$ & & \\
\hline $\begin{array}{l}\text { Outdoor current } \\
\text { transformer installation }\end{array}$ & $\sqrt{ }$ & $\sqrt{ }$ & $\sqrt{ }$ & $\sqrt{ }$ & $\sqrt{ }$ & \\
\hline $\begin{array}{l}\text { Lightning } \quad \text { arrester } \\
\text { installation }\end{array}$ & $\sqrt{ }$ & $\sqrt{ }$ & $\sqrt{ }$ & $\sqrt{ }$ & $\sqrt{ }$ & \\
\hline Power capacitor installation & $\sqrt{ }$ & $\sqrt{ }$ & $\sqrt{ }$ & $\sqrt{ }$ & $\sqrt{ }$ & \\
\hline Fuse installation & $\sqrt{ }$ & $\sqrt{ }$ & $\sqrt{ }$ & $\sqrt{ }$ & $\sqrt{ }$ & \\
\hline Dry reactor installation & $\sqrt{ }$ & $\sqrt{ }$ & $\sqrt{ }$ & $\sqrt{ }$ & & \\
\hline $\begin{array}{l}35 \mathrm{kV} \text { collective shunt } \\
\text { capacitor installation }\end{array}$ & $\sqrt{ }$ & $\sqrt{ }$ & $\sqrt{ }$ & $\sqrt{ }$ & & \\
\hline $\begin{array}{l}10 \mathrm{kV} \text { collective shunt } \\
\text { capacitor installation }\end{array}$ & $\sqrt{ }$ & $\sqrt{ }$ & $\sqrt{ }$ & $\sqrt{ }$ & & \\
\hline
\end{tabular}




\subsection{Project schedule management}

The basic object of schedule information management is the project activity information within the scope of the project, because the project schedule is a complex and changeable

The dynamic process, duration, description of the number of deliverables, completed works, resource consumption and other factors determine the comprehensiveness of the construction schedule. The construction schedule can be simulated by extracting the schedule time attribute in the three-dimensional model to virtualize the construction stage Schedule, compare and analyze the planned construction schedule and the actual construction schedule, real-time dynamic control and integration, to ensure that the construction is completed according to the original plan, to achieve on-site management and control of the substation, control the construction efficiency, and arrange the schedule strictly.

By combining the three-dimensional information model with the construction schedule plan, a 3D+time schedule information model is established to simulate the dynamic process of project construction. In the actual construction, strictly follow the simulated construction schedule, adjust the errors in time, realize the precise control of the project schedule, and reduce the risk of project delay.

\subsection{Engineering quality management}

Project quality information management is a comprehensive work involving all project information management functions and processes, including preproject planning information, plan information, implementation and control quality information, as well as scope information management, duration information management, and cost information Management, organizational information management, communication management, risk information management, procurement information management and other management functions.

Use three-dimensional information model for engineering quality management, mainly to classify and integrate engineering quality information with the standard process control, quality countermeasures control and risk early warning control in the three-dimensional model as the core to form a complete quality information management system to ensure project quality and quality The goals are coordinated and unified. Combined with project schedule management, in different construction stages, early warning and avoidance of standard technology, quality countermeasures, construction risks and other content related to the upcoming construction content can be carried out in advance, and the quality risk control of the substation can be finally realized.

\subsection{Project cost management}

Project cost management is through the means of information management, under the premise of meeting the predetermined quality and construction period requirements, optimizing, filtering, and screening effective cost information, using the key information to take cost control measures, and controlling the total cost of the project at a reasonable level Within range.

The use of three-dimensional information model for project cost management is mainly to add the information required for project budgetary statistics to the model attributes in advance, so that the budgetary statistics can be visualized, digitized, and coordinated in the engineering design, for design units, construction units, and construction management Units and project cost review units bring convenience and efficiency. Combining with the "what you build is what you get" feature in 3D technology, it can achieve accurate statistics on engineering quantities, ultimately achieve cost control, and reduce project construction costs.

On the basis of the full-attribute three- dimensional model, all the cable laying, foundation treatment, structural support installation and other plans of the substation are accurate, the corresponding cable quantity, earthwork quantity, steel quantity, etc. are accurate, and the engineering quantity is completely determined and controllable Therefore, the total cost of the substation can be accurately calculated. Reduce the random increase or decrease workload on site and the risk that the estimate cannot be accurately calculated.

\section{Research on the application of 3D technology in engineering operation and maintenance stage}

The application of 3D technology in the engineering operation and maintenance stage is to use $3 \mathrm{D}$ information model and monitoring technology, combined with realtime data of operation and maintenance related systems, to timely display and monitor the operation status, dynamic data and development trend of operation data of key equipment, so that we can In the virtual reality environment, the spatial location information of the substation, main equipment design parameters (static functional location information), related design drawings, patrol maintenance records, equipment operating status information, key equipment dynamic operating data, and live real-time video monitoring screens are displayed in a centralized manner.

When the user clicks on a device, the system will obtain the code of the current device from the 3D model, query the operating data of the device in the background database, and display the latest data in the display window in the form of a list. Historical data such as temperature, humidity, etc. will be displayed in the form of curves. 


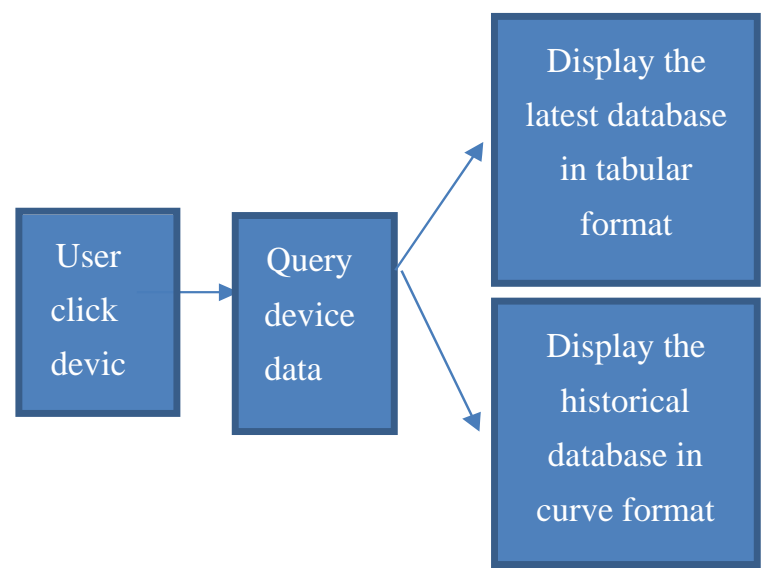

Figure 1. The application of 3D technology in the project operation and maintenance stage

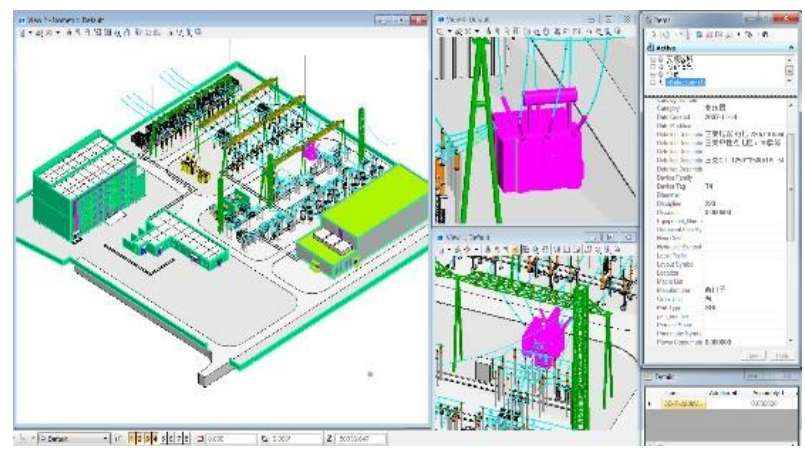

Figure 2. The application effect of $3 \mathrm{D}$ technology in the project operation and maintenance stage

\section{Summary}

Three-dimensional technology is the basis for realizing a new generation of digital, virtual, and intelligent information platforms, and realizes the unification of graphics and engineering data. The essence of the application of 3D technology in engineering design, construction management, operation and maintenance management is the application of data in 3D information models. At each stage, the data attribute information in the three-dimensional information model is extracted, and through different processing methods such as statistics, comparison, analysis, and calculation, the requirements of engineering design, schedule, quality, and cost management are realized.
This paper uses the advantages of the integration of graphics and data in 3D technology and uses it as a data carrier to propose the concept of a full-attribute 3D model, and study the application direction and method of the full-attribute 3D model in the whole process of substation construction., Digital and intelligent project management provide a theoretical basis.

\section{Reference}

1. Hu Junhui, Sheng Dakai, Xi Xin, Qi Lizhong. Building a digital design system and leading the development direction of power grid construction [J]. Electric Power Construction, 2012, 33(12): 1-5.

2. Sheng Dakai, Xie Xin, Hu Junhui, et al. Research and development of grid information model (GIM) technology to build a smart grid information sharing platform $[\mathrm{J}]$. Electric Power Construction, 2013, 34(8): 1-5.

3. Sun Bin. A survey report on the application of three-dimensional technology in the United States and Japan [J]. Electric Power Survey and Design, 2004, 06(5): 8-13.

4. Wu Liangliang. The application prospect of BIM's information sharing function in construction enterprises $[\mathrm{J}]$. China Engineering Consulting, 2013(12):50-51.

5. Zhang Fangning. Construction and research of three-dimensional visualization construction management system for power grid engineering $[\mathrm{J}]$. Science and Technology Innovation Guide, 2016(11):81- 82.

6. Zeng Liang. Research and application of threedimensional technology in domestic power plant design[D]. Changsha: Central South University, 2010.1-4

7. Wang Yili, Wang Shaoning. Three- dimensional technology based on PDMS of Jiangsu Electric Power Design Institute [J]. Industrial Control Computer, 2003, 16(12): 5-6.

8. Liu Xiaodong, Li Chunhong. Research on the development of multi-discipline three- dimensional collaborative design collaboration $[\mathrm{J}]$. Science and Technology Information Development and Economy, 2006, 16(19): 159-161. 